\title{
On the Fringes of Space
}

\section{By JOHN HODGES, Reginia Astronomical, Society, Regina}

During the past year everyone has become aware of man's efforts to explore the atmosphere. Scientists have been using three devices in their studies-balloons carrying radio transmitters have "sounded" the lower layers; rockets have gone higher and reported the conditions they encountered; satellites have been placed even higher and have reported much about the outermost fringes.

Satellites give us information about much more than the matter they must move through in their orbit. They can tell us a great deal about the earth you and I live on. The story of how man came to launch satellites to study the earth goes back to the time of Newton. In his Principia Mathematica, published 300 years ago, Newton outlined the theory of the movement of celestial bodies about the sun. He went so far as to illustrate how a cannon on a mountain top could be used to launch an "artificial" satellite. Just as Newton by observing the moon and planets unlocked the secret of the laws under which they move, so man today, watching an artificial moon, can have it tell him about the earth he stands on.

The moon is an earth satellite. It obeys the laws outlined by Newton. The closer a satellite is to the earth, the faster it must move to remain in a stable orbit, that is, an orbit that the satellite will remain in without hitting the object it is going around. The moon is about 240,000 miles away and goes around us in 27.3 days. The first artificial satellite's third tage rocket was at a mean distance of 315 miles from the earth, and took 46 minutes to complete a trip around us. To put a satellite into an orbit $t$ must be put to the desired altitude and given a velocity almost exactly arallel to the earth's surface. The velocity given to it will depend on the ltitude and it must be very precise. This in itself was a major feat. The aunching of the satellite was also a demonstration of the accuracy of Newton's theories of three hundred years ago.

The moon moves in an ellipse and its distance from us at different positions varies as much as 30,000 miles. What about sputnik? It also moved in an ellipse. The rocket carrier came as close as 130 miles to the earth and moved as far as 500 miles away frcm it each trip around us. There is an important difference, however, between the moon and the satellite. The moon is far beyond our atmosphere, but not so the satellite. Although the atmosphere is very thin 130 miles above the earth, the satellite encountered enough resistance to cause it to gradually come dcwn to the earth.

Satellites will help scientists make reliable long-range weather forecasts. With satellites eventually televising the earth from great heights, much information could be cbtained about the earth's surface, and the movements of air and cloud masses. Satellites provide a means of analysing the make-up of our atmosphere at those high altitudes. Phencmena in the upper atmosphere control to some extent the weather at the surface of the earth. Satellites in their elliptical orbits can radio to earth data about the various layers of the atmosphere through which they pass.

Another important aspect of this study of atmospheric conditions is the effect certain electrical disturbances have on radio communication. When a taxi equipped with radio cannot contact its base but picks up messages from remote stations instead, the upper atmosphere is to blame. Already it is possible to advise about probable conditions for radio reception. It is known that the sun affects the upper atmosphere and the satellites will tell us how.

I believe that satellites will one day make it possible for us to reach the moon. What importance would this have for people interested in natural history? Personally, if I had the chance, the first thing I would lcok for on the moon would be a fossil. Imagine what a story would unfold if there were fossils to prove that life had existed on the moon prior to the time when it lost all its atmosphere. 